\title{
Persistent increase in plasma and urinary leukotrienes after acute asthma
}

\author{
A P Sampson, D P Castling, C P Green, J F Price
}

\begin{abstract}
Leukotrienes may mediate bronchoconstriction in asthma. Cysteinyl leukotriene production rises in vivo after allergen challenge, but few reports describe leukotriene concentrations in clinical asthma or in children. Using high performance liquid chromatography/radioimmunoassay, plasma and urinary leukotrienes in asthmatic children (aged 5-10 years) were measured during an acute exacerbation (peak expiratory flow (PEF) $<65 \%, n=10$ ) and one month later (PEF 74-169\%, $n=9$ ), and in non-atopic normal children (aged 1.3-13.2 years). In the asthmatics, geometric mean $(95 \%$ confidence interval) plasma leukotriene $B_{4}\left(\right.$ LTB $\left._{4}\right)$ was 746 $\mathrm{pg} / \mathrm{ml}$ (398 to 1403$)$ acutely and $1026 \mathrm{pg} / \mathrm{ml}$ (662 to 1593) in remission, compared with $369 \mathrm{pg} / \mathrm{ml}$ (167 to 728 ) in the normal children $(n=14)$. Plasma cysteinyl leukotrienes were low or undetectable, but urinary leukotriene $\mathrm{E}_{4}\left(\mathrm{LTE}_{4}\right)$ was higher in the asthmatics during an acute episode (210 $\mathrm{pmol} / \mathrm{mmol}$ creatinine, 101 to 454 ) and at follow up (179 $\mathrm{pmol} / \mathrm{mmol}, 110$ to 293), compared with the normal children (98 $\mathrm{pmol} / \mathrm{mmol}, 81$ to $118, n=41$ ). This persistent increase in plasma $\mathrm{LTB}_{4}$ and urinary $\mathrm{LTE}_{4}$ concentrations one month after a severe asthmatic episode suggests leukotriene production is related to chronic inflammation rather than to acute bronchoconstriction.
\end{abstract}

(Arch Dis Child 1995; 73: 221-225)

Keywords: leukotrienes, asthma.

It is increasingly accepted that products of lymphocytes of the Th2 subtype including interleukin (IL)-5 and IL-3 may regulate the inflammatory activity of eosinophils and mast cells within the asthmatic lung. ${ }^{1}$ These cells can generate a variety of mediators, toxic enzymes, and oxygen radicals which may account for the airflow obstruction, epithelial damage, and airway hyperresponsiveness of asthma.

Among these products are the lipid mediators cysteinyl leukotrienes (leukotriene $\mathrm{C}_{4}$ $\left(\mathrm{LTC}_{4}\right)$, leukotriene $\mathrm{D}_{4} \quad\left(\mathrm{LTD}_{4}\right)$, and leukotriene $\mathrm{E}_{4}\left(\mathrm{LTE}_{4}\right)$ ), which abundant evidence implicates in airflow obstruction in asthma. ${ }^{2}$ They are potent inducers of bronchoconstriction, ${ }^{3}$ mucus hypersecretion, ${ }^{4}$ and airway oedema. ${ }^{5} \mathrm{LTE}_{4}$ concentrations, used as a marker of whole body cysteinyl leukotriene production, rise after challenge of asthmatics with inhaled allergen ${ }^{6}$ and exercise. ${ }^{7}$ Cysteinyl leukotriene receptor antagonists inhibit both early and late bronchoconstrictor responses to allergen and block the associated increase in bronchial responsiveness, ${ }^{8}$ and they improve lung function and reduce symptoms in chronic asthma. ${ }^{9}$

In contrast, the possible role of leukotriene $\mathrm{B}_{4}\left(\mathrm{LTB}_{4}\right)$ in asthma is unclear. However, it is the most potent lipid chemotaxin known for neutrophils, which are implicated in sudden onset fatal asthma ${ }^{10}$ and in nocturnal asthma, ${ }^{11}$ and also chemoattracts monocytes, lymphocytes, and eosinophils. ${ }^{12}$ In vitro, LTB $_{4}$ induces Th2 lymphocyte production of IL $-5,{ }^{13}$ which may promote eosinophilia in asthma and atopy, and augments the stimulatory effects of IL-4 on immunoglobulin $\mathrm{E}$ production by $\mathrm{B}$ lymphocytes. ${ }^{14} \mathrm{LTB}_{4}$ can be generated by a range of cells within the lung, including mast cells and macrophages, ${ }^{15} 16$ and has been implicated in neutrophil infiltration after segmental allergen challenge in the human lung. ${ }^{17} \mathrm{LTB}_{4}$ has been reliably detected in the bronchoalveolar lavage fluid of asthmatic subjects. ${ }^{18}$

Previous work by our group has shown a two to fivefold increased capacity for $\mathrm{LTB}_{4}$ and $\mathrm{LTC}_{4}$ generation in vitro by the peripheral blood polymorphonuclear leucocytes of stable atopic asthmatic subjects stimulated by calcium ionophore or formyl-met-leu-phe. 1920 In vivo, such an exaggerated leukotriene synthetic response to immunological stimulation within the asthmatic lung might contribute significantly to bronchoconstriction, chronic inflammation, and bronchial hyperresponsiveness. ${ }^{21}$

We aimed therefore to use combined high performance liquid chromatography (HPLC)/ radioimmunoassay techniques to assay $\mathrm{LTB}_{4}$, $\mathrm{LTC}_{4}, \mathrm{LTD}_{4}$, and $\mathrm{LTE}_{4}$ in the plasma, and $\mathrm{LTE}_{4}$ in the urine, of asthmatic children admitted to hospital with an acute exacerbation, and at follow up at least one month later after clinical improvement. Attempts were made to reduce the possible confounding effects of anti-inflammatory medication, and concentrations were compared with those in a control group of normal children with no personal or family history of allergic disease.

\section{Subjects and methods}

CLINICAL CHARACTERISTICS OF SUBJECTS Permission for the study (No B81/89) was obtained from the ethics committee of King's College Hospital. Ten children with acute asthma (aged 5-10 years) were admitted with acute dyspnoea and wheezing. Peak expiratory flow (PEF) was $<65 \%$ of predicted, with nine 
out of 10 having PEF $<40 \%$ predicted. All had taken inhaled $\beta_{2}$-agonists, but only one out of 10 was on inhaled corticosteroids, two were receiving sodium cromoglycate, and none were receiving theophyllines. All had a close family history of atopy, and skin prick tests were positive (two or more allergens) in four subjects tested. Blood and urine samples were taken before treatment with systemic steroids was begun.

Nine of the 10 asthmatic children provided blood and urine samples at follow up at least one month after the acute episode. All were well with PEF $74-169 \%$ of predicted. Although all had received systemic corticosteroid treatment for five days after admission, none had received systemic steroids for at least 25 days preceding the follow up visit. Only two out of nine children were receiving inhaled corticosteroids, and none had received theophyllines for at least 14 days.

Normal children (aged 1.3-13.2 years) with negative personal and family histories of atopy provided blood $(n=14)$ or urine $(n=41)$ as controls. All were healthy with no history of chronic respiratory disease and none were receiving medication.

\section{SAMPLE COLLECTION}

Blood $(10 \mathrm{ml})$ was taken into a heparinised syringe containing the 5-lipoxygenase inhibitor nordihydroguaiaretic acid (NDGA; $50 \mu \mathrm{M}$; Sigma) and the cysteinyl leukotriene bioconversion blockers L-serine-borate (30 $\mathrm{mM}$ ) and L-cysteine $(10 \mathrm{mM})$, to prevent generation or catabolism of leukotrienes in vitro. Urine was collected into a sterile container on ice and an aliquot sent for creatinine determination.

\section{LEUKOTRIENE ASSAYS}

Leukotrienes were assayed as described by us. ${ }^{22}$ Briefly, samples are spiked with tritiated $\left({ }^{3} \mathrm{H}\right)$ leukotriene internal standards before methanol extraction and partial purification on octadecylsilane cartridges (Sep-Pak, Waters). Leukotrienes are separated by high performance liquid chromatography using a $\mathrm{C} 18$ column (Techsphere $250 \times 46 \mathrm{~mm}$ ) with a methanol/water/acetic acid (75/25/0.01; pH 5.6) solvent system, and quantified by radioimmunoassay.

\section{STATISTICAL ANALYSES}

Power calculations on previous data from normal children suggested that differences in geometric mean urinary $\mathrm{LTE}_{4}$ concentrations of approximately twofold would be detectable with $80-90 \%$ probability in groups of $12-15$ subjects each. No reliable data were available with which to perform similar calculations for plasma leukotriene comparisons. Plasma and urinary leukotriene concentrations approximated most closely to $\log _{10}$ normal distributions, and values are therefore given as the geometric mean and $95 \%$ confidence interval (CI). Comparisons between groups were made by paired or unpaired Student's $t$ tests on log normalised values.

\section{Results}

$\mathrm{LTB}_{4}$ CONCENTRATIONS IN PLASMA

Plasma $\mathrm{LTB}_{4}$ concentrations (fig 1) were above detection limits in all subjects except one normal. Geometric mean ( $95 \%$ CI) plasma $\mathrm{LTB}_{4}$ concentrations were $746 \mathrm{pg} / \mathrm{ml}$ (398 to 1403) in the asthmatic subjects during the acute exacerbation $(n=10)$, twice that in the normal subjects (geometric mean 369 $\mathrm{pg} / \mathrm{ml}, 95 \%$ CI 167 to $728 ; \mathrm{n}=14$ ); however, this did not reach statistical significance $(p=0.097)$. Geometric mean plasma $\mathrm{LTB}_{4}$ concentrations rose further at follow up to $1026 \mathrm{pg} / \mathrm{ml}$ (662 to $1593 ; \mathrm{n}=9$ ), which was significantly higher than in the normal subjects $(p=0.012)$.

\section{CYSTEINYL LEUKOTRIENE CONCENTRATIONS IN} PLASMA

Plasma concentrations of $\mathrm{LTC}_{4}$ and $\mathrm{LTD}_{4}$ were below detection limits $(<50 \mathrm{pg} / \mathrm{ml})$ in all asthmatic patients studied $(n=6)$ both acutely and at follow up, and in all normal subjects studied ( $n=6$; data not shown).

Plasma concentration of $\mathrm{LTE}_{4}$, however, were detected in 11 out of 14 normal subjects, and in all asthmatic patients both acutely and in remission (fig 2). In the asthmatics, geometric mean $(95 \% \mathrm{CI})$ plasma $\mathrm{LTE}_{4}$ concentrations were $314 \mathrm{pg} / \mathrm{ml}$ (191 to 517 ) during the acute exacerbation $(\mathrm{n}=10)$ and $348 \mathrm{pg} / \mathrm{ml}$ (189 to 643$)$ at follow up $(n=9)$. Neither of these concentrations was significantly greater $(\mathrm{p}>0.3)$ than the plasma $\mathrm{LTE}_{4}$ concentration in normal subjects (geometric mean 232 $\mathrm{pg} / \mathrm{ml}, 95 \% \mathrm{CI}: 132$ to $406 ; \mathrm{n}=14$ ). The high variability in the normal plasma $\mathrm{LTE}_{4}$ concentrations means that the power of the study to detect small group differences is relatively low. However, an enhancement of the same magnitude as that observed with $\mathrm{LTB}_{4}(2 \cdot 9$-fold),

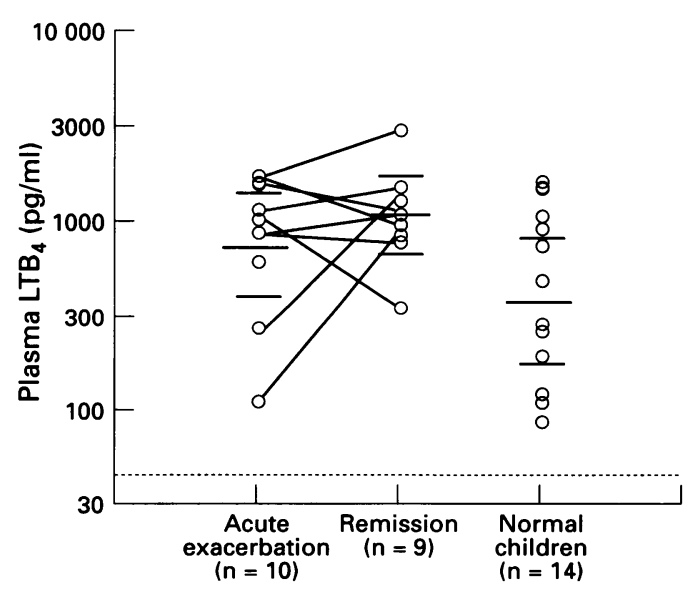

Figure 1 Concentrations of $\mathrm{LTB}_{4}$ (log scale) in the plasma of asthmatic patients during an acute exacerbation and in remission, and in normal children. Horizontal bars indicate geometric mean and $95 \%$ CI; dotted line indicates detection limit of the assay. $L T B_{4}$ concentrations tended to be higher in the asthmatics acutely $(p=0.097)$ than in the normals, and were significantly higher in the asthmatics in remission $(p=0.012)$. 


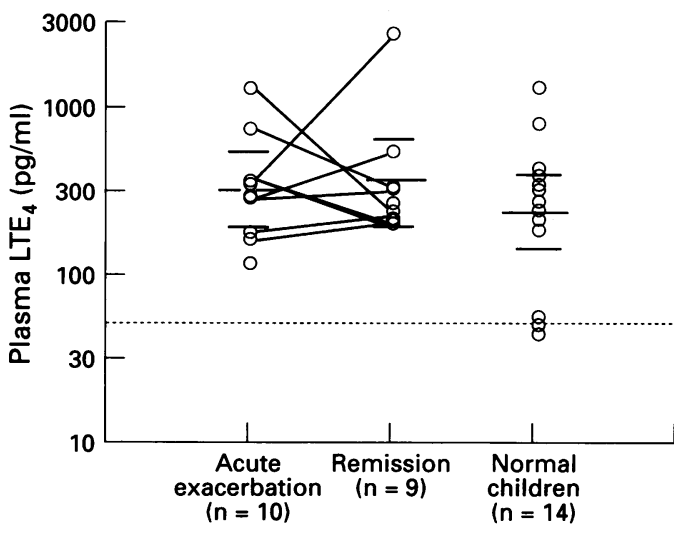

Figure 2 Concentrations of $\mathrm{LTE}_{4}$ (log scale) in the plasma of asthmatic patients during acute exacerbation and in remission, and in normal children. Horizontal bars indicate geometric mean and $95 \%$ CI; dotted line indicates detection limit of the assay. There were no significant differences between the groups.

would be detectable in plasma $\mathrm{LTE}_{4}$ concentrations with a power of approximately $75 \%$; the probability of a significant type II error is therefore low.

\section{URINARY LTE ${ }_{4}$ CONCENTRATIONS}

In contrast to the plasma $\mathrm{LTE}_{4}$ results, a significant increase in urinary $\mathrm{LTE}_{4}$ was apparent in the asthmatic subjects (fig 3). Geometric mean $(95 \% \mathrm{CI})$ urine $\mathrm{LTE}_{4}$ concentration was $219 \mathrm{pmol} / \mathrm{mmol}$ creatinine (101 to 454 ) during the acute exacerbation $(n=10)$ and 179 $\mathrm{pmol} / \mathrm{mmol}$ creatinine (110 to 293 ) at follow up $(n=9)$, both significantly higher than in the normal children (geometric mean $97 \cdot 7,95 \%$ $\mathrm{CI}: 81$ to $118 ; \mathrm{n}=41) \quad(\mathrm{p}=0.0025$ and $\mathrm{p}=0.0085$ respectively)

As plasma and urinary $\mathrm{LTE}_{4}$ concentrations may both reflect whole body production of cysteinyl leukotrienes, we attempted to relate plasma and urine $\mathrm{LTE}_{4}$ values in each subject group. In the normals, $\log _{10}$ plasma $\mathrm{LTE}_{4}$ and $\log _{10}$ urine $\mathrm{LTE}_{4}$ were not significantly correlated $(r=-0.26, \mathrm{p}=0.5 ; \mathrm{n}=14)$. Similarly, in the asthmatic subjects, plasma and urine $\mathrm{LTE}_{4}$ concentrations correlated neither during the acute exacerbation $(r=-0.061$, $\mathrm{p}=0.9 ; \mathrm{n}=10)$ nor at follow up $(r=-0.053$, $\mathrm{p}=0.9 ; \mathrm{n}=9$ ).

\section{Discussion}

We have demonstrated that production of cysteinyl leukotrienes, as reflected in urinary $\mathrm{LTE}_{4}$ concentrations, is significantly higher than normal in asthmatic children not only during an acute asthmatic episode, but also a month later when lung function has returned to normal. Overproduction of these potent bronchoconstrictor mediators in asthma is paradoxically therefore not directly related to acute bronchoconstriction, but may rather reflect an ongoing inflammatory process in the asthmatic lung with a role in bronchial hyperresponsiveness. Moreover, we have demonstrated that plasma values of the proinflammatory compound $\mathrm{LTB}_{4}$ tended to be higher than in normals during the acute asthmatic episode, and were significantly higher than normal at the one month follow up. This supports the concept of an involvement of $\mathrm{LTB}_{4}$ in chronic inflammation in asthma which may be up-regulated by an acute exacerbation.

Our previous findings that both $\mathrm{LTB}_{4}$ and $\mathrm{LTE}_{4}$ are highly stable in whole blood in vitro $^{23} 24$ suggested these leukotrienes as the targets of choice for leukotriene measurement in the circulation. However, leukotrienes are generated in vivo in very small molar quantities, and biological fluids contain nonspecific immunoreactivity that interferes with immunoassays. The importance of internal radiolabelled leukotriene standards, solid phase extraction on $\mathrm{C} 18$ cartridges, and HPLC to purify leukotrienes in biological fluids before immunoassay has been well documented. ${ }^{25}{ }^{26}$ Many early studies of leukotriene concentrations in plasma did not fulfil these methodological requirements, so that early reports of raised concentrations of cysteinyl leukotrienes ${ }^{27-29}$ and of $\mathrm{LTB}_{4}{ }^{30}$ in the plasma of asthmatics must now be treated with caution. In our studies $\mathrm{LTC}_{4}$ and $\mathrm{LTD}_{4}$ were undetectable $(<50 \mathrm{pg} / \mathrm{ml})$ in all subjects, but $\mathrm{LTE}_{4}$ and $\mathrm{LTB}_{4}$ were detected in most normal and asthmatic subjects at concentrations similar to those found by other workers using HPLC/radioimmunoassay techniques. ${ }^{31}$ However, venous plasma $\mathrm{LTE}_{4}$ was relatively low and highly variable, and failed to fully reflect the significantly increased cysteinyl leukotriene production in the asthmatic children that was observed in urinary $\mathrm{LTE}_{4}$ concentrations. Moreover, plasma $\mathrm{LTE}_{4}$ concentrations did not correlate with urinary $\mathrm{LTE}_{4}$. This lack of sensitivity suggests that plasma $\mathrm{LTE}_{4}$ measurements may not be useful as an adjunct to $\mathrm{LTE}_{4}$ urinalysis.

$\mathrm{LTE}_{4}$ concentrations in urine are used as a marker of whole body production of cysteinyl leukotrienes because a fixed proportion $(4-6 \%)$ of ${ }^{3} \mathrm{H}-\mathrm{LTC}_{4}$ infused intravenously in man emerges as ${ }^{3} \mathrm{H}-\mathrm{LTE}_{4}$ in the urine within four hours, irrespective of the dose administered. ${ }^{32}$ Several studies have described an

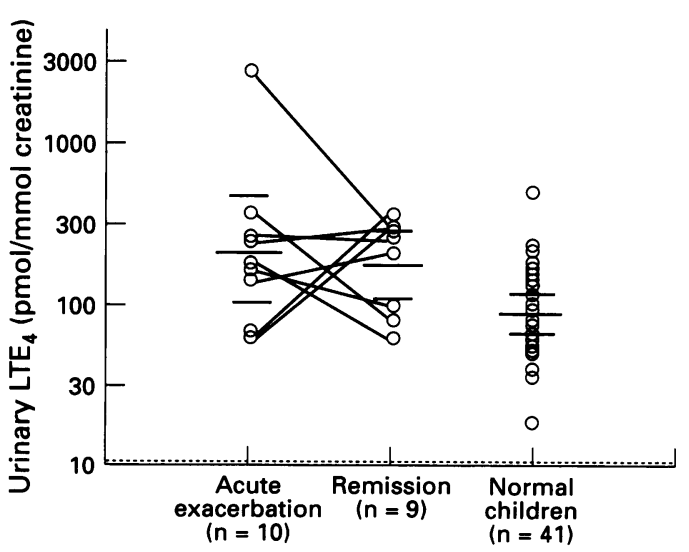

Figure 3 Concentrations of $\mathrm{LTE}_{4}$ (log scale) in the urine of asthmatic patients during acute exacerbation and in remission, and in normal children. Horizontal bars indicate geometric mean and $95 \%$ CI; dotted line indicates detection limit of the assay. Urinary $L_{T E_{4}}$ concentrations were significantly higher in the asthmatics both acutely $(p=0.003)$ and in remission $(p=0.009)$ compared with the normals. 
increase in urinary $\mathrm{LTE}_{4}$ in susceptible asthmatic adults after challenge with allergen, 63334 exercise, ${ }^{7}$ and aspirin. ${ }^{35}$ Relatively few studies have examined urinary $\mathrm{LTE}_{4}$ excretion in relation to the variable lung function of clinical asthma. Taylor and colleagues found increased urinary $\mathrm{LTE}_{4}$ in 20 adult asthmatics admitted to hospital for an acute exacerbation. ${ }^{6}$ Only eight of these asthmatics were re-examined at follow up, and in these subjects urinary $\mathrm{LTE}_{4}$ concentrations had not fallen significantly, despite systemic corticosteroid and theophylline treatment resulting in a return to normal lung function. Increased urinary $\mathrm{LTE}_{4}$ has also been found in a significant proportion of stable adult asthmatics. ${ }^{33}$ In our study, urinary $\mathrm{LTE}_{4}$ concentrations were approximately double normal values both acutely and in remission in asthmatic children suggesting chronic overproduction of the cysteinyl leukotrienes.

There is overwhelming evidence for chronic inflammation in the bronchial mucosa even in mild asthma. Involved in this inflammatory process is a variety of resident cells, including mast cells and macrophages, and infiltrating cells, such as eosinophils, which are capable of generating leukotrienes in response to $\operatorname{IgE}$ dependent stimulation. The source of the enhanced plasma $\mathrm{LTB}_{4}$ and urinary $\mathrm{LTE}_{4}$ we have observed cannot be ascribed with certainty to any one cell type. However, chronic overproduction of $\mathrm{LTC}_{4}$ and $\mathrm{LTB}_{4}$ by cells stimulated by persistent inhalation of environmental allergens might have profound effects beyond immediate bronchoconstriction. The cysteinyl leukotrienes may impede airflow by constricting bronchial smooth muscle, inducing mucus secretion, and promoting airway oedema, but in addition, $\mathrm{LTD}_{4}$ has recently been shown to be a highly potent and specific chemotaxin for human eosinophils in vitro, ${ }^{36}$ and inhaled $\mathrm{LTE}_{4}$ may also directly induce the eosinophil infiltration characteristic of the asthmatic lung. ${ }^{37}$ The putative source of $\mathrm{LTB}_{4}$ is more problematic, as mast cells can generate only limited amounts, while we have shown bronchoalveolar lavage cells $(80 \%$ alveolar macrophages) to have a markedly downregulated capacity for $\mathrm{LTB}_{4}$ synthesis in vitro in mild asthma. ${ }^{38}$ Nevertheless, long term production of $\mathrm{LTB}_{4}$ within the bronchial mucosa may cause infiltration of neutrophils and monocytes into the lung, and the chemotactic potency of $\mathrm{LTB}_{4}$ towards eosinophils ${ }^{12} 39$ is often overlooked. Moreover, eosinophils primed by specific factors such as IL- 5 respond readily to the non-specific chemotaxins $\mathrm{LTB}_{4}$ and IL-8, ${ }^{40}$ and $\mathrm{LTB}_{4}$ may itself promote the production of IL-5 from T lymphocytes. ${ }^{13}$

Our work supports the concept that cysteinyl leukotrienes may have a role in the chronic inflammation in the bronchial mucosa in asthma, and that this may underlie the early indications of an anti-inflammatory and steroid sparing effect of cysteinyl leukotriene receptor antagonists in current clinical trials. The possibility of an involvement also of $\mathrm{LTB}_{4}$ in chronic asthma in children strengthens the case for the further development of 5- lipoxygenase inhibitors which may counteract the actions of both classes of leukotriene. Further studies are called for to investigate the effects of 5-lipoxygenase inhibitors on leukotriene production in long term studies in health and disease.

This study was greatly aided by invaluable advice and guidance from the late Priscilla J Piper, Vandervell Professor of Pharmacology at the Royal College of Surgeons, whose recent death deprives the field of inflammation research of one of its leading exponents.

APS is supported by the Frances and Augustus Newman Foundation, and DPC by the Royal Air Force. We thank Dr R Sherwood (Department of Clinical Biochemistry, King's College Hospital) for performing creatinine analyses, Dr A W College Hospital) for performing creatinine analyses, Dr A W
Ford-Hutchinson (Merck-Frosst Canada) for the kind gift of Ford-Hutchinson (Merck-Frosst Canada) for the kind gift of
$\mathrm{LTB}_{4}$ antiserum, and Professor B Peskar (University of Graz, Austria) for generously donating the cysteinyl leukotriene antiserum.

1 Corrigan CJ, Kay AB. Asthma: role of T-lymphocytes and lymphokines. Br Med Bull 1992; 48: 72-84.

2 Arm JP, Lee TH. Sulphidopeptide leukotrienes in asthma. Clin Sci 1993; 84: 501-10.

3 Barnes NC, Piper PJ, Costello JF. Comparative effects of inhaled leukotriene $\mathrm{C}_{4}$, leukotriene $\mathrm{D}_{4}$, and histamine in normal human subjects. Thorax 1984; 39: 500-4.

4 Coles SJ, Neill KH, Reid LM, et al. Effects of leukotrienes $\mathrm{C}_{4}$ and $\mathrm{D}_{4}$ on glycoprotein and lysozyme secretion by human and $\mathrm{D}_{4}$ on glycoprotein and lysozyme secretion by hun

5 Woodward DF, Weichman BM, Gill CA, Wasserman MA. The effect of synthetic leukotrienes on tracheal microvascular permeability. Prostaglandins 1983; 25: $131-42$

6 Taylor GW, Black P, Turner N. Urinary leukotriene $\mathrm{E}_{4}$ after antigen challenge and in acute asthma and allergic rhinitis. Lancet 1989; i: 584-8.

7 Kikawa Y, Miyanomae T, Inoue Y, et al. Urinary $\mathrm{LTE}_{4}$ after exercise challenge in children with asthma. $\mathcal{F}$ Allergy Clin Immunol 1992; 89: 1111-9.

8 Taylor IK, O'Shaughnessy KM, Fuller RW, Dollery CT. Effect of the cysteinyl-leukotriene receptor antagonist ICI 204,219 on allergen-induced bronchoconstriction and airway hyperreactivity in atopic subjects. Lancet 1991; 337 ; $690-4$.

9 Hui KP, Barnes NC. Lung function improvement in asthma with a cysteinyl leukotriene antagonist. Lancet 1991; 337: 1062-3.

10 Sur S, Crotty TB, Kephart GM, et al. Sudden-onset fatal asthma: a distinct entity with few eosinophils and relatively more neutrophils in the airway submucosa? Am Rev Respir Dis 1993; 148: 713-9.

11 Martin RJ, Cicutto LC, Smith HR, Ballard RD, Szefler SJ. Airways inflammation in nocturnal asthma. Am Rev Respir Dis 1991; 143: 351-7.

12 Czarnetzki BM, Rosenbach T. Chemotaxis of human neutrophils and eosinophils towards leukotriene $\mathrm{B}_{4}$ and its 20 - oxidation products in vitro. Prostaglandins 1986; 31 : 851-8.

13 Yamaoka KA, Kolb J-P. Leukotriene $B_{4}$ induces interleukin 5 generation from human T lymphocytes. Eur $\mathcal{F}$ Immunol 1993; 23: 2392-8

14 Yamaoka KA, Dugas B, Paul-Eugene N, Mencia-Huerta JM, Braquet P, Kolb JP. Leukotriene $B_{4}$ enhances IL-4induced IgE production from normal human lymphocytes. Cell Immunol 1994; 156: 124-34.

15 Freeland HS, Schleimer RP, Schulman ES, Lichtenstein LM, Peters SP. Generation of leukotriene $\mathrm{B}_{4}$ by human lung fragments and purified human lung mast cells. $\mathrm{Am}$ Rev Respir Dis 1988; 138: 389-94.

16 Schonfeld W, Schluter B, Hilger R, Konig W. Leukotriene generation and metabolism in isolated human lung macrophages. Immunology 1988; 65: 529-36.

7 Koh YY, Dupuis R, Pollice M, Albertine KH, Fish JE, Peters SP. Neutrophils recruited to the lungs of humans by segmental antigen challenge display a reduced chemotactic response to leukotriene $\mathrm{B}_{4}$. Am $\mathcal{F}$ Respir Cell Mol Biol 1993; 8: 493-9.

18 Lam S, Chan H, LeRiche JC, Chan-Yeung M, Salari $H$. Release of leukotrienes in patients with bronchial asthma. f Allergy Clin Immunol 1988; 81: 711-7.

19 Sampson AP, Evans JM, Garland LG, Piper PJ, Costello JF. The generation and metabolism of leukotrienes in the ionophore-stimulated blood of normal and asthmatic subjects. Pulm Pharmacol 1990; 3: 111-9.

20 Sampson AP, Thomas RU, Costello JF, Piper PJ. Enhanced leukotriene synthesis in leukocytes of atopic and asthmatic leukotriene synthesis in leukocytes of atopic and

21 Arm JP, Spur BW, Lee TH. The effects of inhaled leukotriene $\mathrm{E}_{4}$ on the airway responsiveness to histamine in subjects with asthma and normal subjects. $\mathcal{f}$ Allergy Clin in subjects with asthma and

22 Sampson AP, Spencer DA, Green CP, Piper PJ, Price JF. Leukotrienes in the sputum and urine of cystic fibrosis Leukotrienes in the sputum and urine of cys

23 Zakrzewski JT, Sampson AP, Evans JM, Barnes NC, Piper PJ, Costello JF. The metabolism in vitro of leukotriene $B_{4}$ in blood of normal subjects and asthmatic patients. Prostaglandins 1988; 35: 869-83. 
24 Zakrzewski JT, Sampson AP, Evans JM, Barnes NC, Piper PJ, Costello JF. The biotransformation in vitro of cysteinyl leukotrienes in blood of normal and asthmatic subjects. Prostaglandins 1989; 37: 425-44.

25 Heavey DJ, Soberman RJ, Lewis RA, Spur B, Austen KF. Critical considerations in the development of an assay for Clasma. Prostaglandins 1987; 33: 693-708.

26 Westcott JY, Johnson K, Batt RA, Wenzel SE, Voelkel NF. Measurement of peptidoleukotrienes in biological fluids. M Appl Physiol 1991; 68: 2640-8.

27 Morris HR, Taylor GW, Clinton PM. Measurement of leukotrienes in asthmatics. In: Samuelsson B, Paoletti R, Ramwell P, eds. Adv Prostaglandin Thromboxane Leukot Ramwell P, eds. Adv Prostaglandin Thromboxan

28 Isono T, Koshigara Y, Murota S, Fukuda Y, Furukawa S Measurement of immunoreactive $\mathrm{LTC}_{4}$ in blood of asthmatic children. Biochem Biophys Res Commun 1985; 130: 486-92.

29 Iwasaki E. Leukotriene $\mathrm{C}_{4}$ in children with atopic asthma: Plasma levels in acute asthma. Acta Paediatr fpn 1989; 31 286-94.

30 Seggev JS, Thornton WH, Edes TE. Serum leukotriene $B_{4}$ levels in patients with obstructive airway disease. Chest 1991; 99: 289-91.

31 Sasagawa M, Satoh T, Takemoto A, Hasegawa T, Suzuk $\mathrm{E}$, Arakawa M. Blood levels of leukotriene $\left(\mathrm{LTC}_{4}, \mathrm{D}_{4}, \mathrm{E}_{4}\right.$ $\left.\mathrm{B}_{4}\right)$ in asthmatic patients during attack and remission. $\mathrm{B}_{4}$ ) in asthmatic patients
Arerugi 1994; 43: 28-36.

32 Maltby NH, Taylor GW, Ritter JM, Moore K, Fuller RW,
Dollery CT. LTC $_{4}$ elimination and metabolism in man f Allergy Clin Immunol 1990; 85: 3-9.

33 Manning PJ, Rokach J, Malo J-L, et al. Urinary leukotriene E levels during early and late asthmatic responses. f Allergy Clin Immunol 1990; 86: 211-20.

34 Westcott JY, Smith HR, Wenzel SE, et al. Urinary leukotriene $\mathbf{E}_{4}$ in patients with asthma: effect of airways reactivity and sodium cromoglycate. Am Rev Respir Dis 1991; 143: 1322-8.

35 Christie PE, Tagari P, Ford-Hutchinson SW, et al. Urinary $\mathrm{LTE}_{4}$ concentrations increase after aspirin challenge in aspirin-sensitive asthmatic subjects. Am Rev Respir Dis 1991; 143: 1025-9.

36 Spada CS, Nieves AL, Krauss AH, Woodward DF. Comparison of leukotriene $\mathrm{B}_{4}$ and $\mathrm{D}_{4}$ effects on huma eosinophils and neutrophil motility in vitro. $\mathcal{f}$ Leukoc Biol 1994; 55: 183-91.

37 Laitinen LA, Laitinen A, Haahtela T, Vikka V, Spur BW, Lee TH. Leukotriene $\mathrm{E}_{4}$ and granulocytic infiltration into asthmatic airways. Lancet 1993; 341: 989-90.

38 Restrick LJ, Sampson AP, Piper PJ, Costello JF. Reduction in $\mathrm{LTB}_{4}$ generation by bronchoalveolar lavage cells in asthma. Thorax 1995; 50: 67-73.

39 Bisgaard $H$, Helqvist $S$, Boudet $L$ Venge $P$, Dahl $R$ Sondergaard J. Chemotactic activity of $\mathrm{LTB}_{4}$ in man. Sondergaard J. Chemotacti

40 Sehmi R, Wardlaw AJ, Cromwell O, Kurihawa K, Waltmann $P$, Kay AB. Interleukin-5 selectively enhances the chemotactic response of eosinophils obtained from normal but not eosinophilic subjects. Blood 1992; 79: 2952-9. 